\title{
Analysis of Transients during the Power System Restoration
}

\author{
Žaneta Eleschová ${ }^{1)}$, Martin Jedinák ${ }^{2)}$ and Rastislav Šmidovič ${ }^{3)}$ \\ 1) Inst. of Power and Applied Electrical Engineering, FEI STU Bratislava, Slovakia, zaneta.eleschova@stuba.sk \\ 2) Slovenská elektrizačná prenosová sústava, a.s. Bratislava, Slovakia, martin.jedinak@sepsas.sk \\ 3) Slovenská elektrizačná prenosová sústava, a.s. Bratislava, Slovakia, rastislav.smidovic@sepsas.sk
}

\begin{abstract}
The paper presents simulation results of transients during the power system restoration. The Defence plan and Restoration plan development is a part of transmission system operator's responsibilities and requires thorough calculations, simulations and publication of instructions. The plans focus on extensive failures that have a heavy impact on the system operation and could lead to a blackout. The Restoration plan of power system has to contain procedures for start-up without outside help. TSO regularly checks some part of the Restoration plan.
\end{abstract}

Keywords - restoration, black-start, restoration route, auxiliary systems, transients.

\section{INTRODUCTION}

Despite the endeavour of transmission system operators (TSO) to design and operate the power system securely, i.e. at least by fulfilment of $\mathrm{N}-1$ criterion, and a low probability of an occurrence of such serious failure as a partial or a complete blackout, experience from real operation shows that this threat is real and quite possible [1].

Every year numerous disturbances within the contemporary power system are detected and recorded. The vast majority of them are handled without serious consequences by automatic designated systems or by human operators. Nevertheless, some of them can lead to a complete failure of a part or even whole system. Changes in conditions related to energy market liberalization create high demands on technical ability of formerly stable system and consequently affect reliability of power generation, transmission and distribution and finally increase the likelihood of a critical event occurrence.

SEPS as a TSO of the control area of Slovakia is according to the Dispatch rules for control of the Slovak Republic power system responsible for the system restoration in case of wide area disturbance, so called blackout.

The re-energisation procedure of the Restoration plan is possible in two ways:

1. top-down re-energisation strategy - in case of capability to support re-energisation from neighbouring TSOs.

2. bottom-up re-energisation strategy - creating the route within the home-restoration procedures.

This paper is focused on the bottom-up re-energisation strategy.

In the case of a blackout system fault, the source of the "black-start capability" support service is required to run an independent power plant to ensure its own power consumption. Or, if the voltage drops, the generator must run if it is equipped with a technology that allows the automatic start and wake-up of the selected generator without an auxiliary power plant to ensure its own consumption. After securing own consumption, the start of the selected generator starts at the command of the SED dispatcher. The local operating regulations must not be violated when the generator is started.

At present, it is not in operation instruction clearly defined, the way of creating the route within the homerestoration procedures (bottom-up re-energisation of power system). In this post, the following alternatives can be considered:

1. Starting the generator at nominal voltage and gradually building the route to the auxiliary systems of the power plant - gradual route creation.

2. Creating a route to the auxiliary systems of the power plant without voltage and then switching the generator to a nominal voltage - simultaneous route creation.

\section{EVALUATION OF THE RESTORATION ROUTE - BOTTOM-UP RE-ENERGISATION}

Within preparation -of the Restoration plan simulations and calculations are required. The simulations and calculations are focusing on the steady-states and the transients during restoration.

Suitability of the route for the power system restoration is evaluated according the next criteria:

1. Evaluation of the route:

- number of equipment and operation activities,

- value of short-circuit power.

2. Evaluation of load flow results:

- reactive power control capabilities of generators for black-start service,

- rms values of voltage on substations on the route,

- value of capacitive charging power.

3. Evaluation of transients:

- voltage drops on terminals of generators during motors starting,

- frequency drops during motors starting,

- voltage drops on $6 \mathrm{kV}$ substations in auxiliary systems of the power plants during motors starting,

- motors start time,

- overvoltage and overcurrent during switch on operations. 


\section{DESCRIPTION OF THE ANALYSED RESTORATION ROUTE}

The analysed restoration route is for re-energisation of the thermal power plant TPP Novaky from the hydro power plant HPP Nosice.

The re-energization process will begin with the start of the HPP Nosice from the shutdown state, with the loss of the external voltage used to cover its own consumption. At the same time, the voltage drop will be applied to cover all lines and substations in the direction of the route. Each auxiliary system operation of substations is supplied in a spare way according to the technical solutions of each substation. After the starting generator G3 in HPP Nosice and the auxiliary systems securing self-consumption in HPP, a route will be created with $110 \mathrm{kV}$ lines (belongs to distribution companies Stredoslovenská distribučná and Západoslovenská distribučná) up to substation R110 kV in the power plant Novaky (ENO A). After supplying the voltage from the HPP Nosice to ENO A, the next step is connecting auxiliary systems of the block TPP Novaky (ENO B). When all the necessary equipment is connected to the start of the $2^{\text {nd }}$ block of TPP (ENO B), it will be flooded and connected to the island. A scheme of the implementation of the test from the HPP Nosice to the TPP Nováky (ENO B) is shown in Fig. 1.

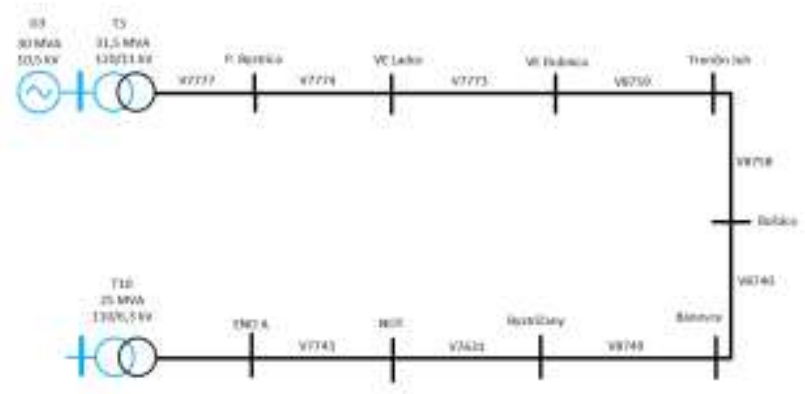

Fig. 1. Single-line diagram of the island operation.

\section{MODEL AND SiMULATIONS OF TRANSIENTS}

The situation for supplying the auxiliary systems of the power plant Nováky (ENO) from the hydro power plant HPP Nosice, was modelled in the ATP program. The aim of the simulations was to point out the occurrence of wave transients related to idling and switching on the selfconsumption transformer in ENO with respect to the nonlinear VA characteristic of the transformer magnetic core. The model is shown in Fig. 2, the results of load flow calculation in steady-state are included.

Reactive power control capabilities of the generator in the HPP Nosice: -24 MVAr, +20 MVAr.

Short-circuit power on $6 \mathrm{kV}$ substation: $50 \mathrm{MVA}$.

Number of equipment on the route:

- generator: 1

- power lines in the distribution network: 9

Capacitive charging power: $-5.8 \mathrm{MVAr}$

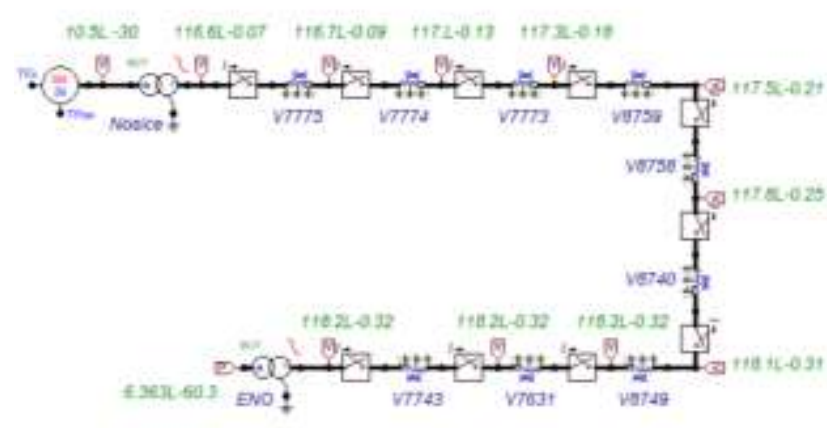

Fig. 2. Simulation model in the program ATP and load-flow results.

\section{A. Transients by the no-load power lines switching}

Switching of the no-load power lines is accompanied by a transient overcurrent and overvoltage. The amplitude of the inrush current is given:

$$
I_{p}=\frac{f_{0}}{f} I_{C}
$$

where the frequency $f_{0}$ of the transient is given by the frequency of the LC circuit, i.e. the parameters of the switching line and the parameters of the other devices (source inductance, transformer parameters, etc.):

$$
\mathrm{f}_{0}=\frac{1}{2 \pi \sqrt{\mathrm{LC}}} \text {. }
$$

The steady capacitive charge current of the line is:

$$
\mathrm{I}_{\mathrm{C}}=\omega \mathrm{CU}_{\mathrm{f}} .
$$

\section{B. Transients by the no-load transformer switching}

When switching on the transformer, the transients may occur. The occurrence and behaviour of such transients already mainly depend on the magnetizing characteristic of the switched transformer, which is nonlinear.

The conditions for ferroresonance are:

- Source of harmonic voltage (generator).

- Ferromagnetic inductance (transformer).

- Capacitance (power line).

- Low active load (no-load restoration route).

All the above conditions are fulfilled during the system restoring.

\section{Simulation results}

Simulations, in addition to proving the transients that accompanied the route building, were also a comparison of 2 approaches for creating a route:

1. Simultaneous route creation: all lines are switched on without voltage and connected to generator voltage in $0.1 \mathrm{~s}$, self-consumption transformer in the TPP Nováky (ENO) was connected in $0.5 \mathrm{~s}$.

2. Gradual route creation: sequential switching on of the elements on the route: self-consumption transformer in the TPP Nováky (ENO) was connected in $1 \mathrm{~s}$.

In the following figures the voltages and currents are plotted. 

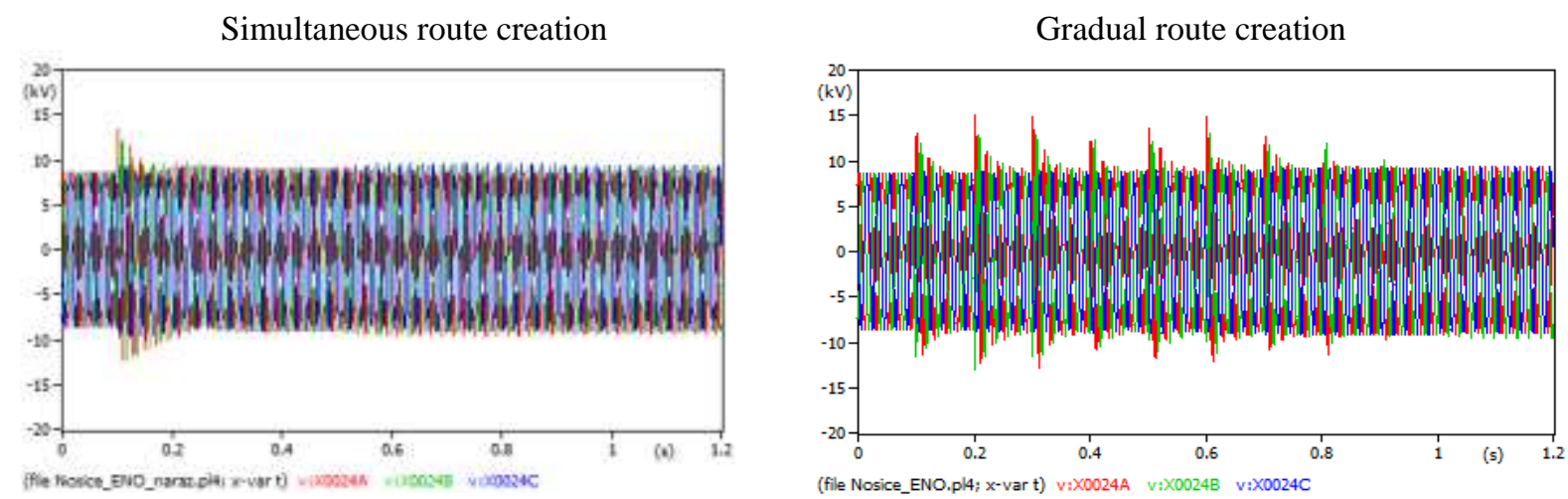

Fig. 3. Voltage - generator in HPP Nosice.
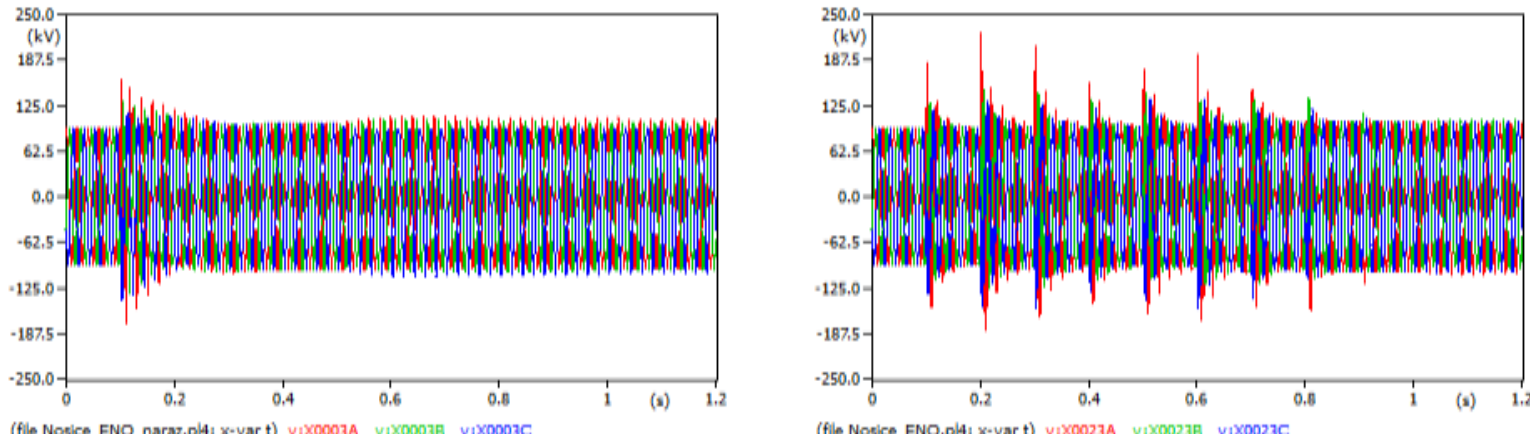

Fig. 4. Voltage $-110 \mathrm{kV}$ substation HPP Nosice.
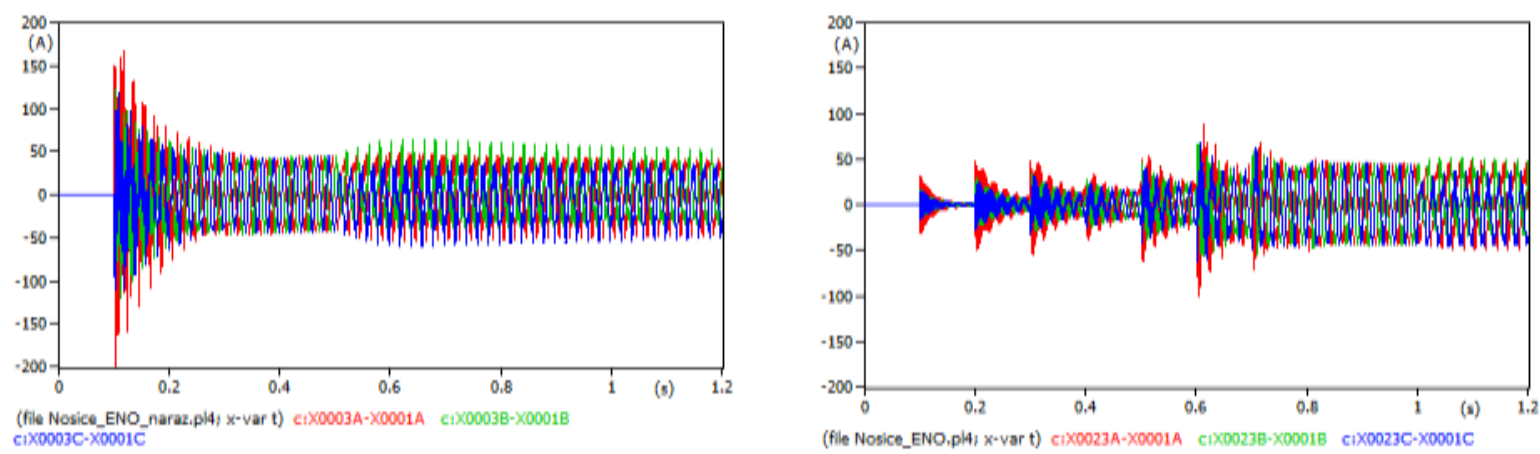

Fig. 5. Current - block transformer HPP Nosice.
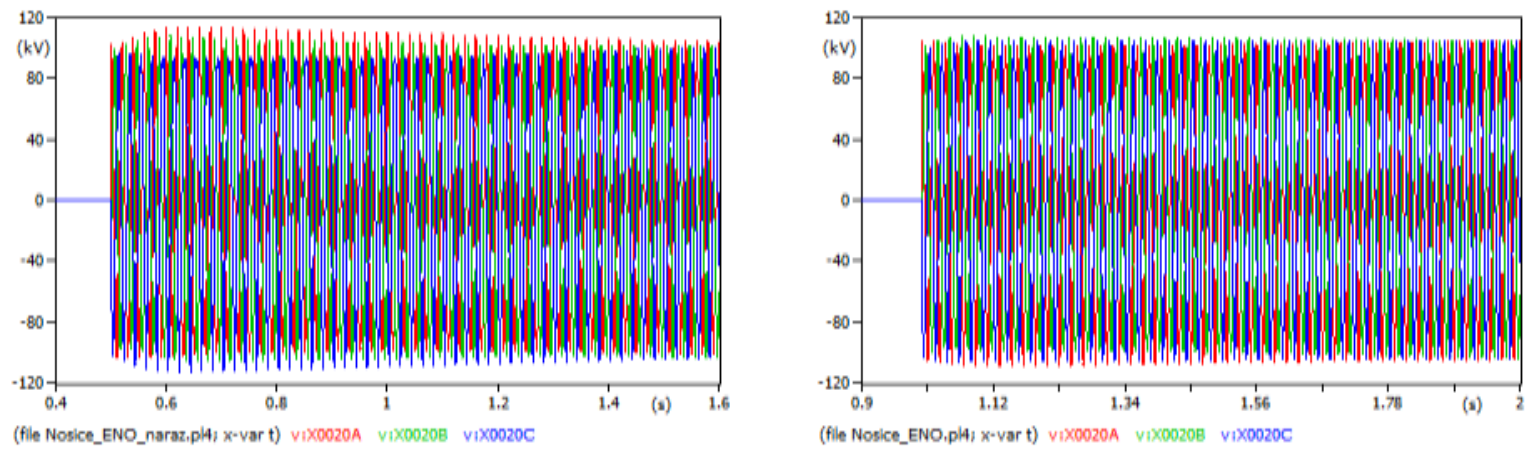

Fig. 6. Voltage - self-consumption transformer in TPP Novaky $-110 \mathrm{kV}$ side. 
Simultaneous route creation

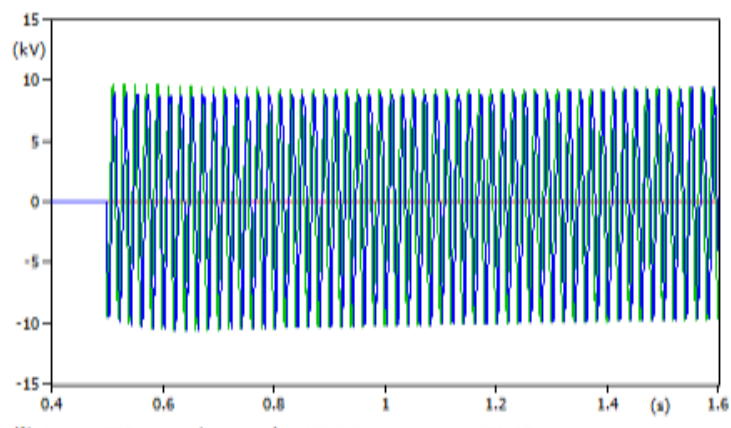

Gradual route creation

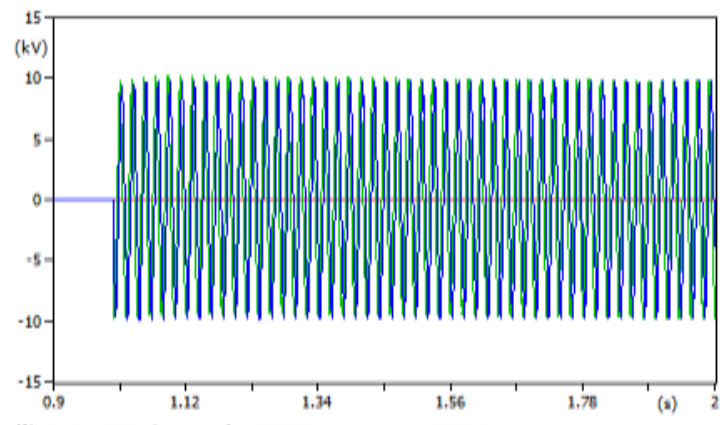

(flle Nosice_ENO,pl4i $\mathrm{x}$-var $t$ ) viX0019A viX00198 viX0019C

(file Nosice_ENO_naraz,pl4i $x$-var t) viXO019A viXO0198 viX0019C

Fig. 7. Voltage - self-consumption transformer in TPP Novaky $-6 \mathrm{kV}$ side.
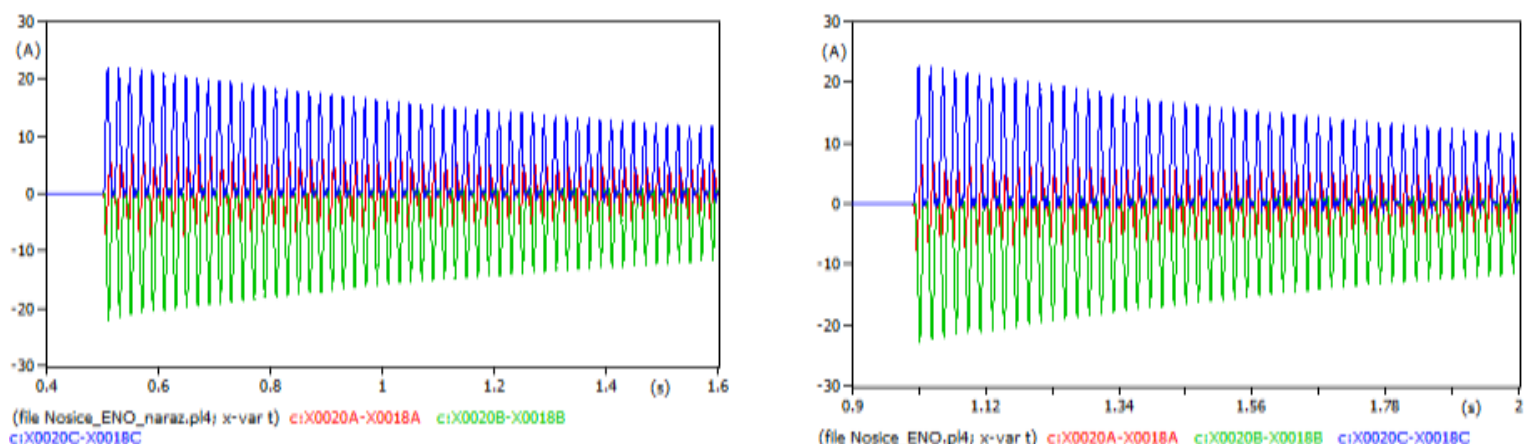

(file Nosice_ENO_naraz,plit/ $x$-var $t$ ) e:X0020A-X0018A ciX0020B-X0018B

(file Nosice_ENO,pl41 X-var t) c1X0020A-X0018A C1X0020B-X0018B c1X0020C-X0018C

Fig. 7. Current - self-consumption transformer in TPP Novaky.
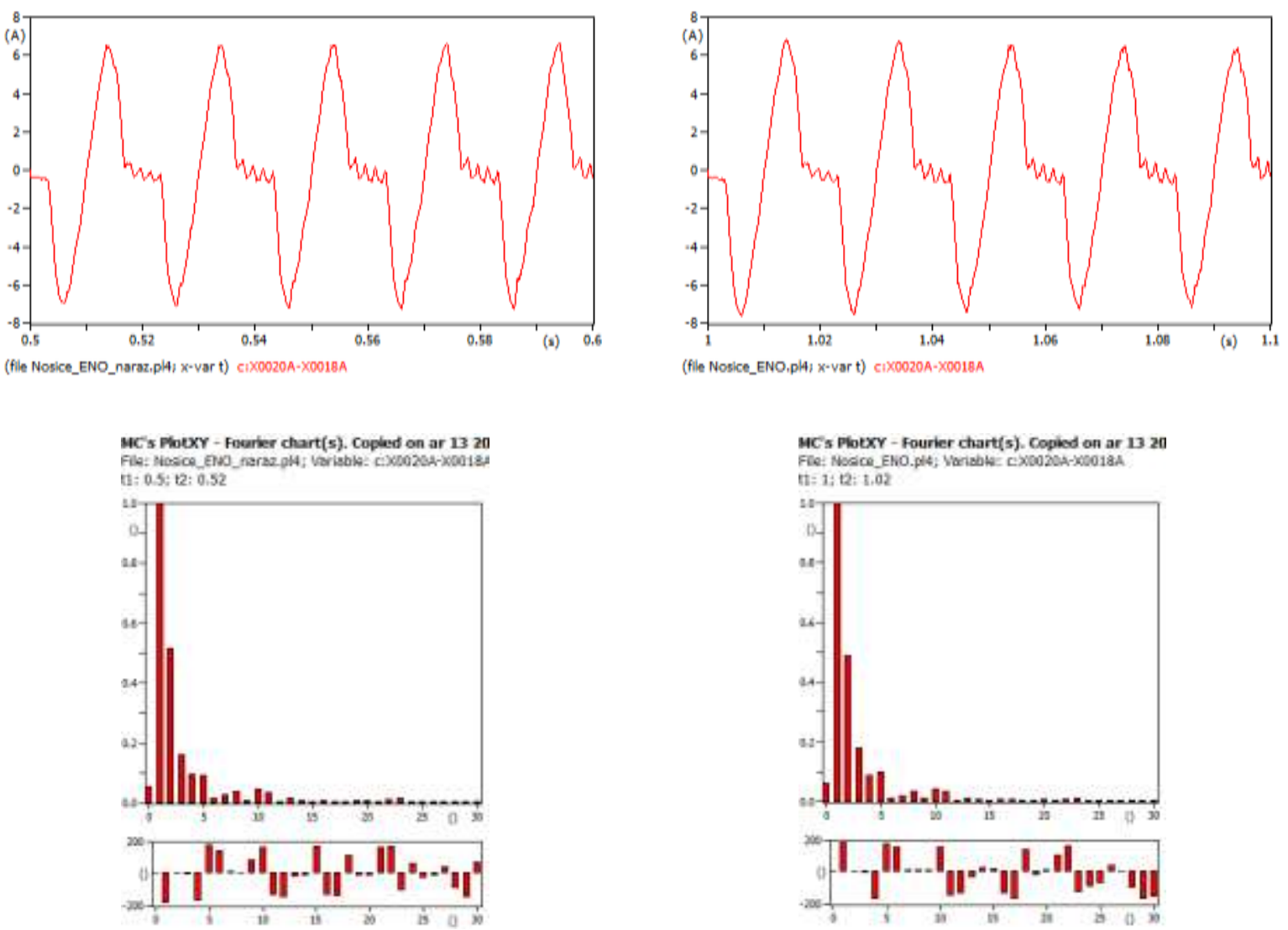

Fig. 8. Details of no-load current - self-consumption transformer in TPP Novaky - L1 phase. 
Simultaneous route creation

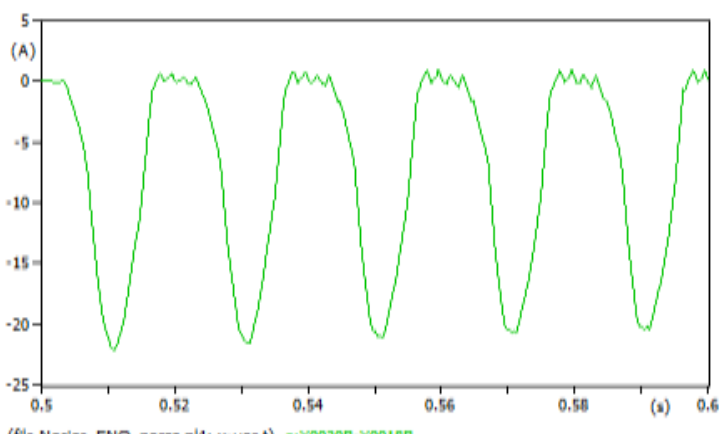

(file Nosice_ENO_naraz,pliti $x$-var t) c1X00208-X00188
Gradual route creation

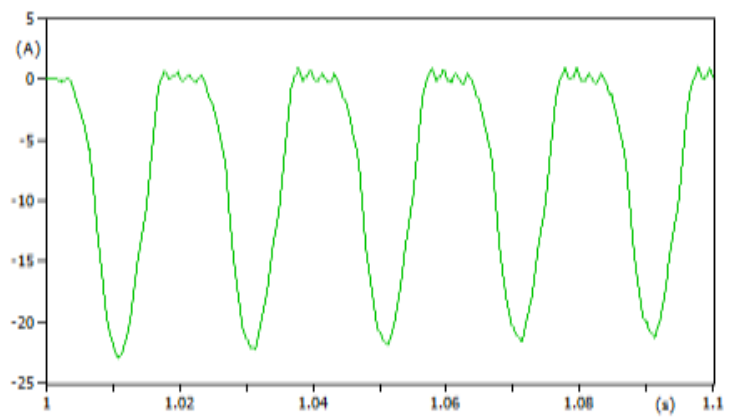

(file Nosice_ENO,pl4i $x$-var $t$ ) c1X00208-X00188

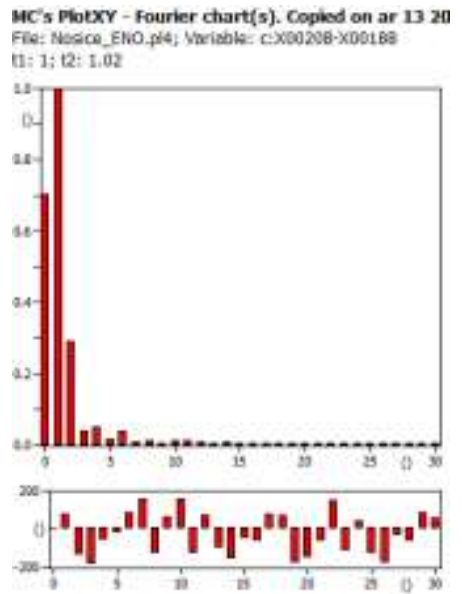

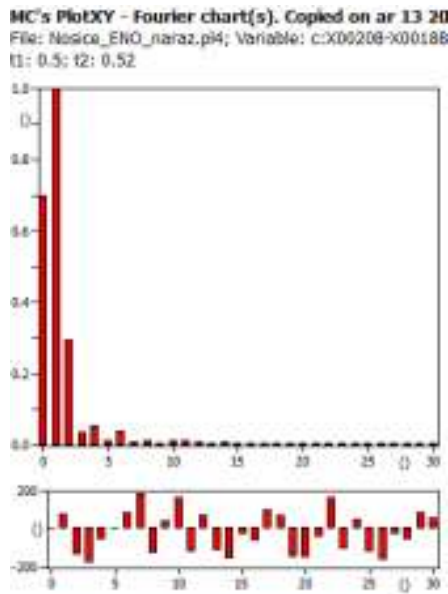

Fig. 9. Details of no-load current - self-consumption transformer in TPP Novaky - L2 phase.

In the figures above it is possible to see the difference between the transients for restoration route building gradually and simultaneously. The difference is in the amplitude of the transient line charging current. When the route is switched on at the same time, this current is given by the capacitances of all lines (the circuit is only a onetime overcurrent and the amplitude is higher) and in the case of the switching on of the lines step by step, the amplitude of the overcurrent is given only by the capacitance of the already switched line (several overcurrents in the circuit).

Switching on the transformer is also connected by an overcurrent, which is characterized by a DC component and $2^{\text {nd }}$ harmonic, as seen from the FFT analysis of the noload transformer current (Fig. 8, 9) [5]. Steady-state noload current is shown in Fig. 10, where there are significant: $3^{\text {rd }}, 5^{\text {th }}$ and $7^{\text {th }}$ harmonics.
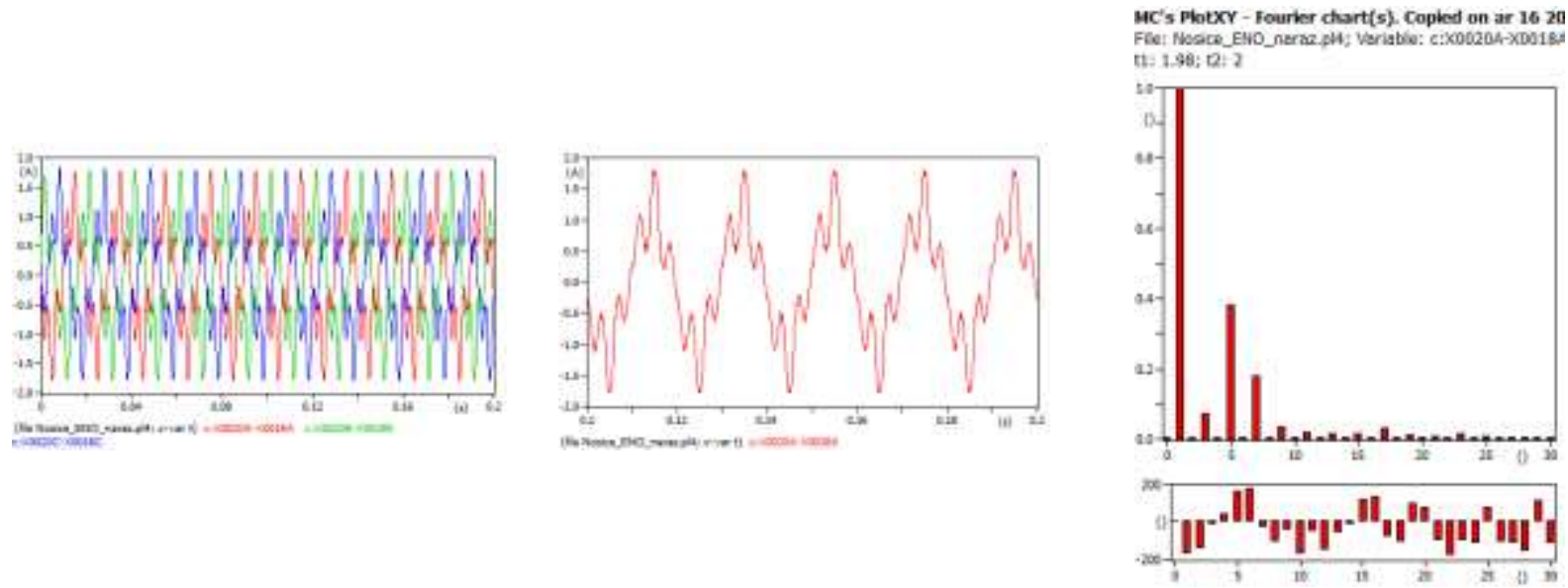

Fig. 10. No-load current of transformer in steady-state (3 phases, detail of L1 phase, FFT analysis). 
There is not a significant difference in the transient voltage nor current during switching on gradually or simultaneously. One reason is the magnetization characteristic of the transformer, which is another reason for a relatively high value of $110 \mathrm{kV}$ power lines resistance, which positively affects the transients.

\section{CONCLUSION}

Preparation of the power system restoration after a blackout is an important part of the Restoration plan. Black-starts, island operation and system resynchronization are very rare cases, but a grid operator should be prepared. The computer simulation is usually used for planning, test preparing and post-process analysis. It enables to investigate dynamic behaviour of the power system during the above-mentioned cases [3].

According to the obtained load-flow results and transient simulations results we can say that the analysed route for re-energisation of the TPP Novaky from the HPP Nosice is suitable. The calculation proved that there is not risk of ferroresonance phenomena (these phenomena caused unsuccessful black-start test in 1996 [2]). The conclusion is that analysed route can be used for the Restoration plan of the power system of the Slovak Republic.

\section{REFERENCES}

[1] K. Máslo a kol., Řizení a stabilita elektrizační soustavy, 2003, AEM, ISBN 978-80-260-44671-1, 272 str.

[2] K. Máslo, and J. Fantík, "Electromechanical and Electromagnetic Phenomena During Power System Restoration," in IXth Int. Scientific Conf. EE '98, St. Lesná 1998

[3] I. Chemišinec, J. Tůma, and K. Witner, "Př́ípravy na řešení havarijních stavů v elektrizační soustavě “ in Proceedings of the 6th International Scientific Conference Electric Power Engineering EPE, Dlouhé Stráně, Czech Republic, 2005

[4] A. Greenwood, Electrical transients in power systems, 2. ed., New York: John Wiley \& Sons, 1991, ISBN 0-471-62058-0.

[5] F. Janíček, V. Chladný, A. Beláň, and Ž. Eleschová, Digitálne ochrany elektrických strojov. ELFA Košice, 2000.

[6] M. Jedinák, R. Šmidovič, and Ž. Eleschová, "The Simulation Test of Black-Start Capacity in Western Part of Slovakia", in Proceeding of the 13th International scientific conference Control of Power System 2018, Tatranské Matliare, Slovakia. June 5-7, 2018, ISBN 978-80-89983-01-8. 